Amjath, M.R., Chandanie, H. and Amarasinghe, S.D.I.A., 2021. Energy retrofits for improving energy efficiency in buildings: A review of HVAC and lighting systems. In: Sandanayake, Y.G., Gunatilake, S. and Waidyasekara, K.G.A.S. (eds). Proceedings of the $9^{\text {th }}$ World Construction Symposium, 9-10 July 2021, Sri Lanka. [Online]. pp. 290-301. DOI: https://doi.org/10.31705/WCS.2021.25. Available from: https://ciobwcs.com/papers/

\title{
ENERGY RETROFITS FOR IMPROVING ENERGY EFFICIENCY IN BUILDINGS: A REVIEW OF HVAC AND LIGHTING SYSTEMS
}

\author{
M.R. Amjath ${ }^{1}$, H. Chandanie ${ }^{2}$ and S.D.I.A. Amarasinghe ${ }^{3}$
}

\begin{abstract}
It has been observed that inefficient buildings consume three to five times more energy than efficient buildings. Subsequently, improving the Energy Efficiency (EE) of existing buildings, which account for a significant portion of the energy consumption of the building sector, has become a top priority. Also, Heating, Ventilation, and Air Conditioning (HVAC) and lighting systems typically account for three-quarters of a building's energy consumption. Hence, focus on the energy efficiency improvements associated with these subsystems is entailed to optimise the energy use of buildings in comparison to other energy consumers. Energy Retrofit (ER) is defined as the main approach in improving the energy efficiency of buildings to achieve energy reduction goals. Nevertheless, there is a general lack of awareness regarding ER. Thus, the purpose of this article is to bridge this research gap by critically reviewing the applicable literature on ER. The paper first analysed the role of retrofits in buildings concerning optimising energy performance. The paper also discusses the implementation process of $E R$, which includes five steps viz. pre-retrofit survey, energy auditing, and performance assessment, identification of suitable and feasible retrofit options, site implementation and commissioning, and validation and verification. Further, different types of ER applicable to HVAC and lighting systems are discussed. In their endeavor to enhance the EE of existing buildings, practitioners could apply the findings of this study, as a basis to understand the available ER types and as a measure to gauge the efficiency of existing buildings, which will facilitate effective decisionmaking.
\end{abstract}

Keywords: Building sector; Energy Retrofits (ER); Heating, Ventilation and Air Conditioning (HVAC); Lighting systems.

\section{INTRODUCTION}

Over the past decades, limited energy sources and gradually increasing energy demands have created an inevitable energy crisis for all nations. If all nations continue with their present energy consumption pattern, demand for energy sources will be doubled in 2030 in comparison with its current level (Birol, 2007). Current predictions reveal that the building industry is responsible for a huge amount of energy consumption, whilst multiple buildings use a large amount of energy (Zuo et al., 2012). Moreover, 29\% of the global

\footnotetext{
${ }^{1}$ Department of Building Economics, University of Moratuwa, Sri Lanka, amjethkhan1995@ gmail.com

${ }^{2}$ Department of Building Economics, University of Moratuwa, Sri Lanka, chandanieh@uom.lk

${ }^{3}$ Department of Building Economics, University of Moratuwa, Sri Lanka, isuria@uom.lk
} 
energy demand is derived from the building sector, and annually this percentage increases by $1 \%$ (Wu et al., 2015). Buildings, demanding energy throughout their total lifecycle from their construction to demolition, and the operation phase are identified as an $80 \%$ $90 \%$ contributor to buildings' life cycle energy demand (Gamage and Lau, 2015). Further, many types of research reveal that the substitute rate of existing buildings by the new buildings is only around 1.0-3.0\% per annum, whilst existing buildings consume a large amount of energy than newly constructed buildings.

Due to these reasons, mechanisms to enhance energy efficiency in existing buildings have become a vital concern even if energy efficiency techniques are to be incorporated and promoted for all newly constructed buildings and if upcoming buildings were to be constructed (Ma et al., 2012). The authors further stated that incorporating energy efficiency techniques in newly constructed buildings will only influence their future energy demands and such an effort can only decrease future energy demands (while there is an energy crisis presenting in the current world). Hence, concerns on energy efficiency in existing buildings are crucial to coping with the timely enhancement of global energy demand and global energy crisis (Asadi et al., 2012).

Total electrical energy consumption of buildings is mainly dependant on the operation of sub-level components such as Mechanical, Electrical, and Plumbing (MEP) systems integrated with the building (Zhao and Magoulès, 2012). According to U.S. Villar and Joutz (2006), in most buildings, the energy consumption of Heating, Ventilation and Air Conditioning (HVAC) systems make up 51\% of total energy consumption, and lighting accounts for $25 \%$ of total energy consumption. At the same time, vertical transportation, pumps, and other equipment account for (5-10\%) and (5-10\%), respectively. As energy consumption of HVAC and lighting are combined, they are typically responsible for three-quarters of the building's energy utility. Hence, more than other energy consumers, it is usually vital to focus on energy-efficient improvements related to these subsystems to optimise the energy consumption of buildings (Zhao and Magoulès, 2012).

Whilst buildings are often open to energy-saving potentials, retrofitting plays an important role in reducing energy consumption by identifying energy-saving opportunities (Dascalaki and Santamouris, 2002). Retrofitting is recognised as a systematic process of investigating the energy-saving potential available in the existing buildings and perform necessary upgrades for energy efficiency improvements (Rysanek and Choudhary, 2013). Moreover, retrofitting actions focus more on optimising the energy efficiency of the existing building while complying with a pre-defined standard benchmark and in compliance with occupants' expectations on thermal, visual, air quality comforts (Dascalaki and Santamouris, 2002).

The energy use of buildings is projected to increase by $1.7 \%$ per annum until 2025, and the great potential for energy reduction in existing buildings can be achieved through the introduction of energy retrofit measures (Shen et al., 2019). Hence, there is increasing pressure worldwide to retrofit existing buildings to have higher energy performance (Ruparathna et al., 2016). Besides, the introduction and development of policies, regulations, building codes, (Palmer et al., 2013), and sustainability protocols such as LEED imply that retrofitting of existing inefficient buildings is critical in meeting regulatory codes and standards (Kontokosta, 2016). Although the world is under pressure to retrofit existing buildings with higher energy performance, the adoption and implementation of ER are still relatively low. Hence, based on the critical review of the 
literature, the paper discusses ER implementation process, different ER measures, and different types of ER that could be useful in retrofitting HVAC and lighting systems of buildings.

\section{RESEARCH METHODOLOGY}

An extensive literature review was essential to solidify the research base by gathering prevailing knowledge in the research area. Hence, a comprehensive literature review is conducted to identify the role of ER in building to optimise energy performance, ER implementation process, and different types of ER that could be taken to retrofit HVAC and lighting systems. At the first stage, to limit the scope of the research, keywords search in the available search engines, 'Scopus', 'Google Scholar', 'Science direct' and 'Emerald'. Several keywords were applied in finding related publications. For example, the following keywords were used: 'ENERGY RETROFITS AND BUILDING SECTOR', 'ENERGY RETROFITTING PROCESS', 'ENERGY RETROFITS AND HVAC SYSTEM' and 'ENERGY RETROFITS AND LIGHTING SYSTEM'. Besides, conference proceedings, book chapters, commercial web pages, and publicly available publications were also reviewed to gain a broad understanding and evaluate the concept of ER. Altogether 60 peer-reviewed articles and commercial publications were reviewed. The search was conducted for the period from 2000-2020. Hsieh and Shannon (2005) stated that the content analysis method is the most used to interpret qualitative text data through systematic coding and patterns. Content analysis has been selected as the most suitable analysis method for this research. The scope of this research is to identify demand-side energy retrofit options for improving energy efficiency in buildings. Due to time constraints, this study is limited to HVAC and lighting systems among all identified MEP systems.

\section{LITERATURE REVIEW}

\subsection{ENERGY AND BUILDINGS}

In recent decades' energy has become an indispensable factor to run this world (Juan et al., 2010). Zhao and Magoulès (2012) explained that a great deal of effort is ongoing to find methods for optimising world energy consumption and to reduce the sources, which are exerting more pressure on energy resources. The authors further stated that universally, demand for energy sources is derived from the main three sectors; i.e. (i) building sector, (ii) industrial sector, and (iii) transportation sector. Among these identified sectors, the building sector consumes a substantially large amount of energy throughout its whole lifecycle (Juan et al., 2010).

Recently, due to increasing population growth and the upward forces for building services with enhanced user expectations on comfort levels, together with the increase in occupied time inside buildings have forced the building sector to consume energy at very high levels. This level of high energy consumption has exceeded that of industrial energy consumption and energy consumption for transportation. Studies by Zhao and Magoulès (2012) reveal that buildings demand energy throughout their whole life cycle but a comparatively large amount of energy consumption is recorded during its operation stage due to the operation and maintenance of a large number of MEP systems. It is identified that in most buildings energy consumption of the HVAC systems is $51 \%$ of total energy usage and the energy consumption of lighting systems is $25 \%$ of total energy consumption 
(Ma et al., 2012). The combination of both the energy consumption of HVAC and lighting systems is typically responsible for three-quarters of the total energy demand of buildings (Hendron, 2013).

Moreover, Ozturk (2013) indicated that the energy utilised by buildings is still highly inefficient and there are immense possibilities for energy performance improvement. The rising demand for energy-efficient buildings has led all nations to seriously consider exploring methods to optimise energy efficiency in buildings (Ouyang and Hokao, 2009). On another hand, it is identified that most buildings seem to welcome energy efficiency improvements, which can be achieved through incorporating ER (Hendron, 2013).

\subsection{ROLE OF RETROFITS IN BUILDING TO OPTIMISE ENERGY Performance}

According to the Oxford English Dictionary [OED], (2017) "retrofitting" can be defined as "incorporate something with a system or feature which is not fitted during manufacture or to add a system component or system feature to any system or building that did not have it when firstly constructed". Further, retrofit is recognised as the process of renovating the systems and structure of buildings to reduce energy consumption for energy efficiency improvements (Alm et al., 2005). Global researchers have proved that a reduction of 50-70\% can be achieved in the energy consumption of buildings by implementing ER measures (Ürge-Vorsatz and Herrero, 2012). However, every building has its unique aspect with different energy characteristics. Therefore, ER techniques and approaches that suit one building may not be suitable for another building (Chidiac et al., 2011). Ma et al. (2012) identified that many interdependent factors such as geographic location, building type, size, age, occupancy schedule, sources of energy, national utility rate structure, operation, and maintenance procedures, building fabric, services, and systems comprised have influenced the process of selecting suitable ER measures. Accordingly, energy retrofitting a building is a complex job. Hence, it has to be performed as a well-organised step-by-step process (Ma et al., 2012).

\subsection{ENERGY RETROFITTING IMPLEMENTATION PROCESS}

The ER process begins with a pre-retrofit survey. This phase focuses on setting scope and targets for the ER process and the entire operations that are to be carried out (Alm et al., 2005). Moreover, in this phase, building owners will determine the required financial and physical resources to implement the project and to select an expertise service that will enable the company with the implementation of the entire retrofitting process (Department of Agriculture, Water and the Environment, 2010). The feasibility and success of the retrofitting process depend on the right understanding of problems identified during the building operation together with the main concerns of the occupants. Hence at this stage, a prerequisite of the pre-retrofit survey is to identify these necessities (Ma et al., 2012).

The next stage of retrofitting process is inclusive of an energy audit and performance assessment (Ma et al., 2012). The purpose of conducting an energy audit is for evaluating building energy trends, identifying building energy utility patterns, identifying areas with energy-saving potentials, and determining cost-effective and financially feasible energy conservation measures (International Performance Measurement and Verification Protocol [IPMVP], 2001). Further, diagnostics are also being conducted in this phase to identify the use of inefficient equipment in operations, improper control systems, 
operational conditions, occupant behaviours, and any malfunctions identified in the building operation (Alm et al., 2005).

The third stage helps with identifying suitable and feasible retrofit options amongst available alternatives by considering energy models, economic analysis tools, and risk assessment methods. Energy Performance Benchmarking (EPB) helps to identify potential areas and possible amount of energy savings and quantitative performance assessment of retrofit alternatives in this phase and which may also require identifying the most beneficial retrofit option amongst multiple alternatives (IPMVP, 2001). Moreover, retrofit alternatives are also prioritised in this phase by considering energyrelated and non-energy-related factors (Ma et al., 2012).

According to the Australian Energy Performance Contracting Association (AEPCA) (2004), the fourth stage is known as the implementation and commissioning phase. Once the most suitable retrofit option is selected, it has to be implemented in the necessary locations. Then, Testing and Commissioning ( $\mathrm{T}$ and $\mathrm{C}$ ) need to be carried out against baselines provided by energy benchmarking, to ensure that retrofit measures keep the building and systems at an optimal level of energy efficiency (AEPCA, 2004).

The process of validation and verification is identified as the final stage of the ER process. Once the decision is made to implement the most suitable retrofit option it has to be welltuned based on the results of energy audit and performance assessment, standard validation, and verification (Braun et al., 2014). The authors further stated that various methods can be used to verify potential energy savings achieved through the retrofit implementation process. A post-occupancy survey is a prerequisite in this phase to verify building professionals and that occupants are satisfied with the overall retrofit process and its result (Ma et al., 2012).

\subsection{TYPES OF BUILDING ENERGY RETROFITS}

As explained in the advanced energy retrofit guide (Hendron, 2013), energy retrofitting can be performed through three globally accepted approaches; i.e. (i) Existing Building Commissioning (EBC), (ii) Standard retrofit, and (iii) Deep retrofits.

The process of upgrading operational behaviours of buildings and the organisation and, implementation of building maintenance procedures is commonly referred to as EBC (Zazzara, 2004). The author further explained that EBC enables buildings to reduce up to $25 \%$ of their present energy consumption level. Optimising operation and maintenance procedures of buildings and MEP systems is the primary aspect of EBC (Sellers and Irvine, 2001). The author further states that "operations" focus on controlling and optimising the energy performance of equipment and systems installed in buildings. Meanwhile, "maintenance" focuses on periodical physical exercises that are carried out to ensure a continuous function or decline of equipment and systems.

Hendron (2013) has defined standard retrofitting as a systematic process that proposes component-level upgrades for systems and equipment to promote energy efficiency in building. The author further explains that standard retrofitting lets buildings achieve a 25$45 \%$ of reduction in the present energy consumption level of buildings.

Blush (2010) explains that deep retrofit measures focus on providing combined design proposals and procedures by considering the performance of the entire MEP systems. 
Ma et al. (2012) explains that more than $45 \%$ of energy savings are achievable through deep retrofit implementations and that it requires a larger initial investment outlay.

All type of buildings has their unique requirements and opportunities for ER. Moreover, there are several energy-efficient retrofit measures available for every specific system. Hence, understanding and identifying those measures is crucial in implementing an effective retrofit procedure.

\subsection{BuILDING ENERGY RETROFIT MEASURES}

In general, ER technologies can be classified under three categories; i.e. (i) supply-side management, (ii) demand-side management, and (iii) occupants' behaviour management (Yu et al., 2011). The process of providing alternative sources to enhance energy efficiency is known as supply-side management ERs. Demand-side management techniques focus on reducing the total energy demand of buildings to enhance energy efficiency (Nakagami, 1996). Further, the occupant's behaviour management measure fully focuses on promoting behavioural changes and user awareness to reduce building energy demands (Yu et al., 2011). Ma et al. (2012) explain that there are plenty of retrofit technologies readily available for the industry. The scope of this research is narrowed to consider the demand-side management techniques focusing on HVAC and lighting systems. The combination of energy consumption of HVAC and lighting is typically responsible for three-quarters of a building's energy utility (Zhao and Magoulès, 2012). Hence, in comparison with other energy consumers, it is of importance to focus on energy-efficient improvements related to these subsystems to optimise the energy consumption of buildings (Zhao and Magoulès, 2012).

\section{Retrofit measures applicable for HVAC}

HVACs are the largest energy consumers in every building (Dessouky et al., 2004). Therefore, retrofit improvements to enhance the energy performance of HVAC systems have a great impact in significantly reducing the energy requirements (Vakiloroaya et al., 2014).

\section{- Optimum Start-Stop Strategy}

Optimum start-stop strategy is referred to as one of the main HVAC control strategies used to avoid unoccupied operations of HVAC (Rahman et al., 2011). The authors further explain that optimum start/stop systems can help with detecting starting time early enough to turn on HVAC components at the optimum time to reach the indoor temperature setpoint at the initiation of scheduled occupancy. Further, this system can detect the optimum stop time of Air Handling Units (AHU) when the indoor air temperature is appropriate enough to maintain the comfort level till the end of the occupancy period (Korolija et al., 2011). An optimum start-stop strategy can help to reduce the load on the equipment and helps with optimising the operation of the system and economising the hours to eliminate waste (Vakiloroaya et al., 2014).

- Installing Variable Frequency Drives (VFD)

Miller et al. (2012) stated that most of the motors are designed to operate at a predetermined constant speed to provide continual constant output. However, many applications and work practices require variable speeds under different circumstances. Moreover, motor operating speed has a high influence on energy when used to run electric motors. On another hand, mostly HVACs are operated at part-load conditions. Therefore, 
during an HVAC operation, whilst HVACs are operating at part load conditions, electric motors operate at full load or at a constant speed, which can lead to energy inefficiencies. Hence, matching the output level or speed of electrical motors with the HVAC load condition can help with eliminating unnecessary energy wastages of electrical motors. Systems such as electric motors have a provision through VFDs to maintain energy efficiency by varying the speed of the electric motor based on the HVAC operational load conditions (Saidur et al., 2012).

- Use of Thermal Storage Systems (TSS)

TSS are systems used to enable the shift of electricity usage of HVAC systems from peak hours to off-peak hours. TSS helps to avoid unnecessary peak-hour charges to help with reducing the burden posed by CEB where high charges are introduced during peak-hour utilities than off-peak or day-time utilities (İnall and Esen, 2004). TSS uses pre-cool water during off-peak hours and this chilled water is stored at low temperature (normally $<200^{\circ} \mathrm{C}$ ) in an in-build sump. This could be used by HVACs during peak hours to produce cool air. Alternatively, TSS also uses pre-heated water during off-peak hours, and this hot water is stored (usually $>200^{\circ} \mathrm{C}$ ) in an in-built insulated sump. This could be used by HVACs during peak hours to produce hot air (Kaygusuz, 2002). Moreover, TSS offers various advantages for conventional HVAC systems such as energy savings and capital cost savings, system operation improvements, system capacity extending and equipment size reduction (İnall and Esen, 2004).

- Free cooling application

The author further states that this technique is often identified as the economiser cycle (Yao and Wang, 2010). This system is used to reduce the workload that is carried out by HVAC systems by using the cooling capacity of the ambient environment (Yao et al., 2004). Moreover, air from the outdoor environment could be used in this system as a cooling medium for indoor cooling instead of cool air supplied by HVACs if the ambient air is chilled enough to achieve an indoor temperature setpoint (Bulut and Aktacir, 2011). Two types of economizers could be used in the free cooling process; i.e. (i) airside economisers and (ii) waterside economisers (Florides et al., 2002). Air-side economisers use the cooling capacity of ambient air directly to fulfil the requirements of indoor cooling. On the other hand, water-side economisers use ambient air to chill condenser water which circulates through the cooling tower (Yao and Wang, 2010). These systems also use a combination of both fresh and return air to fulfil a part of the indoor cooling requirement (Yao and Wang, 2010).

\section{- Energy Recovery Ventilator (ERV)}

ERVs are being used in HVACs to pre-condition ambient air intake by HVAC exhaust air through an energy transferring mechanism and pre-conditioned air is being used, as supply air intake of HVAC systems (Rasouli et al., 2013). When ambient air is preconditioned through ERV at a certain temperature, the cooling load requirement of the HVAC system can be reduced and it can enable HVACs to consume a low amount of energy for indoor cooling (Zhang and Xiao, 2008).

- Demand Control Ventilation (DCV)

To comply with the cooling and any other requirement, the HVAC system which supplies cool air to the indoor environment has to be conditioned. Hence, it consumes a lot of 
energy to process it (Chao and $\mathrm{Hu}, 2004$ ). As a result, a ventilation control system is required to avoid over-ventilation in HVAC operations, if not it may lead to a lot of energy wastages. DVCs can be used to overcome this, as DVC systems calculate the number of occupants considering the fresh air required for a person and based on this the fresh air supply could be controlled. (Wang, 2014). DVCs have enabled HVACs to reduce expenses incurred through unnecessary energy consumption when using ventilation processes that are not economical (Chao and $\mathrm{Hu}, 2004)$.

\section{Retrofit measures applicable to lighting systems}

Lighting systems are often recognised as the second-largest energy consumer in every type of building and often they also show significant influence on energy consumption patterns of HVACs (Bangali and Shaligram, 2012). Therefore, incorporating retrofit technologies for lighting systems has become a vital concern in promoting energy reductions in building energy (Chang et al., 2012).

- Light Emitting Diode (LED) lighting

The use of LED lamps instead of any other type of lamp can introduce much potential to help reduce the electricity demand. This is because LED lamps utilise a very low amount of energy for their operation (Bing, 2012).

- Occupancy based control

The primary objective of occupancy-based lighting control is illuminating lighting systems only when indoor space is occupied (ElMaraghy et al., 2017). Occupancy-based control systems have to install occupancy detection sensors along with Passive Infrared (PIR) and RF-Radar technologies in occupancy areas and integrating them with lighting control units (Ahn et al., 2014). Further, these control units automatically switch on or switch off lighting systems based on the presence of indoor occupancy conditions (Sahoo, 2014).

\section{- Task Lighting}

Greater energy savings can be achieved through this technology, as the lighting power density of task lighting is lower and illumination can be provided to task lights only when and where it is required. Moreover, task lighting arrangements enhance safety and occupant satisfaction too (Dubois and Blomsterberg, 2011).

- Automatic lighting control system

An automatic lighting control system is a technology used to optimise the operating time of a lighting system to minimise the energy demand of lighting systems. Automatic lighting control systems are comprised of various devices to control the operating time of lamps based on, occupancy, working time, and presence of daylight such as occupancy sensor technologies, Passive Infrared (PIR), and ultrasonic sensors (Haq et al., 2014).

- Daylight-linked lighting controls

Buildings that have the potential to allow daylight can enhance energy savings by integrating daylight-linked lighting controls and by using daylighting sources instead of artificial lighting sources whenever possible without any interruptions (Dubois and Blomsterberg, 2011). Daylight-linked controls help to light systems to switch on or off artificial light sources at an optimum level by considering the presence of daylight (Guo, 2010). Moreover, daylight-linked lighting controls are beneficial not only to ensure that 
artificial lights are turned off during daytime but also to control unnecessary illumination beyond the required level (Haq et al., 2014).

- Lighting controlled by time scheduling

This system can automatically switch on and switch off lights based on pre-determined schedules (Flourentzou and Roulet, 2002). Since scheduling systems operate lighting units based on the time it is only feasible for areas where the times of occupancy can be accurately predicted (Diakaki et al., 2008). Moreover, these technologies can facilitate automated commands to turn off the lights completely after occupancy and during weekends and public holidays (Flourentzou and Roulet, 2002).

\subsection{RECOMMENDATIONS FOR IMPROVING BUILDING ENERGY RETROFITS}

Retrofitting of existing buildings provides important opportunities for decreasing global energy consumption. Further, retrofitting of existing buildings is considered to be one of the key approaches to achieving sustainability in the built environment at a relatively low cost. Even though the adoption and implementation of building ER are still relatively low. Hence, academia could actively participate in educating, training, and motivating the use of the ER concept. Informational and inspiring seminars and publishing books are some tools that could be used to promote the application of building ERs. Awareness programs could be conducted by selecting representatives from the government and construction industry, for increasing understanding of how to effectively conduct a building retrofit to promote energy conservation and sustainability. Stakeholders in the construction industry should use the ER concept to formulate policies. The internal organisational policy could be reformed, redesigned, and reorganised to promote the building ER implementation in the construction industry (Bartiaux et al., 2014). Further, governments should provide subsidies and other types of financial support to assist building developers and owners in achieving the applicable energy performance targets through implementing building ERs (Ma et al., 2012; Achtnicht et al., 2014). Further, it is beneficial to develop an action plan to incorporate ER literacy into undergraduate and post-graduate programs. Most courses provide an introductory level of knowledge. Nevertheless, their depth of coverage is insufficient to provide a comprehensive knowledge base for the practical application of building ERs. Therefore, reorganising mainstream education programs by combining concepts related to ERs into related subject areas provides students with tremendous opportunities to apply suitable building ER in the future.

\section{CONCLUSIONS AND THE WAY FORWARD}

This study provided a comprehensive overview of the ER concept. ER has been identified as one of the best opportunities to improve the EE of existing buildings, mainly through the modernisation or modification of building elements or systems. The paper also discusses the ER implementation process, which includes five steps viz. pre-survey, energy audit and performance evaluation, identification of suitable and feasible retrofit options, on-site implementation and commissioning, and validation and verification. Further, different ER measures such as EBC, standard retrofit, and deep retrofits that can be used to improve the $\mathrm{EE}$ of various building elements and building services have also been collected after reviewing articles related to the research area. Besides, the various types of ER-associated with HVAC system (i.e. Optimum start-stop strategy, installing VFD, use of TSS, use of the free cooling application, installing ERV and installing DCV) 
and lighting system (i.e. use of LED lighting, use of occupancy-based control, task lighting, automatic lighting control system, daylight-linked lighting controls, lighting controlled by time scheduling) were discussed to determine the most appropriate type of ER that could be adopted based on needs and context. The findings of this study can help industry practitioners to have a better understanding and have more clarity of the importance of ER, the ER implementation process, the possible ER measures and ER types applicable to HVAC, and lighting systems that can be beneficial to industry practitioners in their endeavour to improve the EE of their facilities. Further, research can be carried out to determine the ER types applicable to the Sri Lankan conditions.

\section{REFERENCES}

Achtnicht, M. and Madlener, R., 2014. Factors influencing German house owners' preferences on energy retrofits. Energy Policy, 68, pp. 254-263.

Ahn, B.L., Jang, C.Y., Leigh, S.B., Yoo, S. and Jeong, H., 2014. Effect of LED lighting on the cooling and heating loads in office buildings. Applied Energy, 113, pp. 1484-1489.

Alm, E., Boland, I., Cobb, V., Eaton, E., Newcomer, M., Pajkowska, J., Perl, Y., Wallentine, L. and Zeller, A., 2005. Workshop in applied earth system policy analysis. In Final Workshop Report, Columbia University, New York, NY.

Asadi, E., Da Silva, M.G., Antunes, C.H. and Dias, L., 2012. Multi-objective optimization for building retrofit strategies: A model and an application. Energy and Buildings, 44, pp. 81-87.

Australian Energy Performance Contracting Association, 2004. A best practice guide to measurement and verification of energy savings. Commonwealth of Australia, Technical Report.

Bangali, J.A. and Shaligram, A.D., 2012. Energy efficient lighting control system design for corridor illumination. International Journal of Scientific and Engineering Research, 3.

Bartiaux, F., Gram-Hanssen, K., Fonseca, P., Ozolina, L. and Christensen, T.H., 2014. A practice-theory approach to homeowners' energy retrofits in four European areas. Building Research and Information, 42(4), pp. 525-538.

Bing, L.Y., 2012. On thermal structure optimization of a power LED lighting. Procedia Engineering, 29, pp. 2765-2769.

Birol, F., 2007. Energy economics: A place for energy poverty in the agenda? The Energy Journal, 28(3).

Blush, A., 2010. Impact of ASHRAE standard 189.1-2009 on building energy efficiency and performance.

Braun, M.R., Altan, H. and Beck, S.B.M., 2014. Using regression analysis to predict the future energy consumption of a supermarket in the UK. Applied Energy, 130, pp. 305-313.

Bulut, H. and Aktacir, M.A., 2011. Determination of free cooling potential: A case study for Istanbul, Turkey. Applied Energy, 88(3), pp. 680-689.

Chang, M.H., Das, D., Varde, P.V. and Pecht, M., 2012. Light emitting diode's reliability review. Microelectronics Reliability, 52(5), pp. 762-782.

Chao, C.Y.H. and Hu, J.S., 2004. Development of a dual-mode demand control ventilation strategy for indoor air quality control and energy saving. Building and Environment, 39(4), pp. 385-397

Chidiac, S.E., Catania, E.J.C., Morofsky, E. and Foo, S., 2011. A screening methodology for implementing cost effective energy retrofit measures in Canadian office buildings. Energy and Buildings, 43(2-3), pp. 614-620.

Dascalaki, E. and Santamouris, M., 2002. On the potential of retrofitting scenarios for offices. Building and Environment, 37(6), pp. 557-567.

Department of Agriculture, Water and the Environment (2010). Climate change. [Online] Available from: https://www.environment.gov.au/climate-change [Accessed 10 April 2010].

Dessouky, H., Ettouney, H. and Al-Zeefari, A., 2004. Performance analysis of two-stage evaporative coolers. Chemical Engineering Journal, 102(3), pp. 255-266.

Diakaki, C., Grigoroudis, E. and Kolokotsa, D., 2008. Towards a multi-objective optimization approach for improving energy efficiency in buildings. Energy and Buildings, 40(9), pp. 1747-1754. 
Dubois, M.C. and Blomsterberg, A., 2011. Energy saving potential and strategies for electric lighting in future North European, low energy office buildings: A literature review. Energy and buildings, 43(10), pp. 2572-2582.

ElMaraghy, H.A., Youssef, A.M., Marzouk, A.M. and ElMaraghy, W.H., 2017. Energy use analysis and local benchmarking of manufacturing lines. Journal of Cleaner Production, 163, pp. 36-48.

Florides, G.A., Tassou, S.A., Kalogirou, S.A. and Wrobel, L.C., 2002. Measures used to lower building energy consumption and their cost effectiveness. Applied Energy, 73(3-4), pp. 299-328.

Flourentzou, F. and Roulet, C.A., 2002. Elaboration of retrofit scenarios. Energy and Buildings, 34(2), pp. 185-192.

Gamage, W. and Lau, S.S., 2015. Perception of indoor environment quality in differently ventilated workplaces in tropical monsoon climates. Procedia Engineering, 118, pp. 81-87.

Guo, X., Tiller, D.K., Henze, G.P. and Waters, C.E., 2010. The performance of occupancy-based lighting control systems: A review. Lighting Research and Technology, 42(4), pp. 415-431.

Hendron, B., 2013. Advanced energy retrofit guide: Practical ways to improve energy performance; grocery stores (Revised)(Book)(No. NREL/BK-5500-54243; DOE/GO-102012-3655). National Renewable Energy Lab: (NREL) Golden, CO (United States).

İnall, M. and Esen, H., 2004. Experimental thermal performance evaluation of a horizontal ground-source heat pump system. Applied Thermal Engineering, 24(14-15), pp. 2219-2232.

IPMVP Committee, 2001. International performance measurement and verification protocol: Concepts and options for determining energy and water savings, Volume I (No. DOE/GO-102001-1187; NREL/TP-810-29564). National Renewable Energy Lab., Golden, CO (US).

James, E.H. and Wooten, L.P., 2005. Leadership as (Un) usual: how to display competence in times of crisis. Organizational Dynamics, 34(2), pp. 141-152.

Juan, Y.K., Gao, P. and Wang, J., 2010. A hybrid decision support system for sustainable office building renovation and energy performance improvement. Energy and Buildings, 42(3), pp. 290-297.

Kaygusuz, K. and Kaygusuz, A., 2002. Geothermal energy: Power for a sustainable future. Energy Sources, 24(10), pp. 937-947.

Kontokosta, C.E., 2016. Modeling the energy retrofit decision in commercial office buildings. Energy and Buildings, 131, pp. 1-20.

Korolija, I., Marjanovic-Halburd, L., Zhang, Y. and Hanby, V.I., 2011. Influence of building parameters and HVAC systems coupling on building energy performance. Energy and Buildings, 43(6), pp. 12471253.

Ma, Z., Cooper, P., Daly, D. and Ledo, L., 2012. Existing building retrofits: Methodology and state-of-theart. Energy and Buildings, 55, pp. 889-902.

Miller, P., Olateju, B. and Kumar, A., 2012. A techno-economic analysis of cost savings for retrofitting industrial aerial coolers with variable frequency drives. Energy Conversion and Management, 54(1), pp. 81-89.

Nakagami, H., 1996. Lifestyle change and energy use in Japan: household equipment and energy consumption. Energy, 21(12), pp. 1157-1167.

Ouyang, J. and Hokao, K., 2009. Energy-saving potential by improving occupants' behavior in urban residential sector in Hangzhou City, China. Energy and Buildings, 41(7), pp. 711-720.

Oxford English Dictionary [OED], 2017. Philippine English in the Oxford English Dictionary: Recent advancements and implications for ESL in the Philippines. Volume 19 July 2017, p. 45.

Ozturk, S., Sozdemir, A. and Ulger, O., 2013. The real crisis waiting for the world: Oil problem and energy security. International Journal of Energy Economics and Policy, 3, p. 74.

Palmer, K., Walls, M., Gordon, H. and Gerarden, T., 2013. Assessing the energy-efficiency information gap: results from a survey of home energy auditors. Energy Efficiency, 6(2), pp. 271-292.

Rahman, M.M., Rasul, M.G. and Khan, M.M.K., 2011. Feasibility of thermal energy storage systems in an institutional building in subtropical climates in Australia. Applied Thermal Engineering, 31(14-15), pp. 2943-2950. 
Rasouli, M., Ge, G., Simonson, C.J. and Besant, R.W., 2013. Uncertainties in energy and economic performance of HVAC systems and energy recovery ventilators due to uncertainties in building and HVAC parameters. Applied Thermal Engineering, 50(1), pp. 732-742.

Ruparathna, R., Hewage, K. and Sadiq, R., 2016. Improving the energy efficiency of the existing building stock: A critical review of commercial and institutional buildings. Renewable and Sustainable Energy Reviews, 53, pp. 1032-1045.

Rysanek, A.M. and Choudhary, R., 2013. Optimum building energy retrofits under technical and economic uncertainty. Energy and Buildings, 57, pp. 324-337.

Sahoo, L.K., Bandyopadhyay, S. and Banerjee, R., 2014. Benchmarking energy consumption for dump trucks in mines. Applied Energy, 113, pp. 1382-1396.

Saidur, R., Mekhilef, S., Ali, M.B., Safari, A. and Mohammed, H.A., 2012. Applications of variable speed drive (VSD) in electrical motors energy savings. Renewable and Sustainable Energy Reviews, 16(1), pp. 543-550.

Sellers, D. and Irvine, L., 2001. Commissioning to meet space qualification criteria vs. energy consumption optimization focused commissioning. In Proceedings of the 2001 International Conference on Enhanced Building Operations. [Online] Available from: www.peci.org/library/PECI_CxCriteria1_1002.pdf.

Shen, P., Braham, W. and Yi, Y., 2019. The feasibility and importance of considering climate change impacts in building retrofit analysis. Applied Energy, 233, pp. 254-270.

ul Haq, M.A., Hassan, M.Y., Abdullah, H., Rahman, H.A., Abdullah, M.P., Hussin, F. and Said, D.M., 2014. A review on lighting control technologies in commercial buildings, their performance and affecting factors. Renewable and Sustainable Energy Reviews, 33, pp. 268-279.

Urge-Vorsatz, D., 2012. Energy end use: Buildings [Online]. Available from: www.iiasa.ac.at/web/home/research/Flagship/Projects/GlobalEnergyAssessment/Ch apte10.en.html [Accessed 15 April 2021].

Ürge-Vorsatz, D. and Herrero, S.T., 2012. Building synergies between climate change mitigation and energy poverty alleviation. Energy Policy, 49, pp.83-90.

Vakiloroaya, V., Samali, B., Fakhar, A. and Pishghadam, K., 2014. A review of different strategies for HVAC energy saving. Energy Conversion and Management, 77, pp. 738-754.

Villar, J.A. and Joutz, F.L., 2006. The relationship between crude oil and natural gas prices. Energy Information Administration, Office of Oil and Gas, pp. 1-43.

Wang, E., Shen, Z. and Grosskopf, K., 2014. Benchmarking energy performance of building envelopes through a selective residual-clustering approach using high dimensional dataset. Energy and Buildings, 75, pp. 10-22.

Wu, R., Du, H. and Wu, Q., 2015. Research on Value-Engineering-based Construction Costs of EnergySaving Buildings. In Applied Mechanics and Materials (Vol. 744, pp. 2310-2313). Trans Tech Publications Ltd.

Yao, Y. and Wang, L., 2010. Energy analysis on VAV system with different air-side economizers in China. Energy and Buildings, 42(8), pp. 1220-1230.

Yao, Y., Lian, Z., Liu, S. and Hou, Z., 2004. Energy-cost allocation based on the theory of frequency response. Applied Energy, 79(4), pp. 371-383.

Yu, Z., Fung, B.C., Haghighat, F., Yoshino, H. and Morofsky, E., 2011. A systematic procedure to study the influence of occupant behavior on building energy consumption. Energy and Buildings, 43(6), pp. 1409-1417.

Zazzara, J.B. and Ward, D.F., 2004. Case Study: Supermarket commissioning with an emphasis on energy reduction. In Proceedings of the National Conference on Building Commissioning, pp. 18-20.

Zhang, L.Z. and Xiao, F., 2008. Simultaneous heat and moisture transfer through a composite supported liquid membrane. International Journal of Heat and Mass Transfer, 51(9-10), pp. 2179-2189.

Zhao, H.X. and Magoulès, F., 2012. A review on the prediction of building energy consumption. Renewable and Sustainable Energy Reviews, 16(6), pp. 3586-3592.

Zuo, J., Read, B., Pullen, S. and Shi, Q., 2012. Achieving carbon neutrality in commercial building developments - Perceptions of the construction industry. Habitat International, 36(2), pp. 278-286. 